\title{
In for a Penny, in for a Pound? A Lifecycle Model for Agile Teams
}

\author{
Phil Diegmann \\ University of Cologne \\ diegmann@,wiso.uni-koeln.de
}

\author{
Tim Dreesen \\ University of Cologne \\ dreesen@,wiso.uni-koeln.de
}

\author{
Christoph Rosenkranz \\ University of Cologne \\ rosenkranz@,wiso.uni-koeln.de
}

\begin{abstract}
Agile methods are increasingly popular - in information systems development and in general. The process of transformation, however, is not easily done, and the inherent barriers for successful transformation are high. To successfully transform a team or a whole organization to work in an agile manner, the threats, barriers, and the overall process have to be known. In this paper, we derive a lifecycle model of agile teams as well as threats to their success, based on interviews from six cases across a variety of industries and organizational contexts. This model further includes pathways for teams to discard agile methods if these do not fit the team's needs. Based on this model, organizations can refine their agile transformation strategies and can keep on improving success rates of agile transformation processes.
\end{abstract}

\section{Introduction}

Agile information system development (AISD) methods are increasingly popular in research and industry [9, $20,21,32]$. With increasing adoption of agile methods, and outgrowing the field of pure information systems development [12], a need for organizational transformation and continued AISD team management has arisen, and it has become even more important to understand the mechanisms of action at play to avoid costly project failures $[32,46,51]$.

While change management and AISD method tailoring as well as adoption have been covered by extant research [e.g., 21, 26], some organizations have even become less agile than before their agile transformation [41]. Further, research on team-level effects and especially on the processes involved when transforming teams is scarce $[9,36]$, as literature focuses on method tailoring [e.g., 10, 21], method adoption [24, 36], or organizational transformation [e.g., 31, 45]. Additionally, change management literature so far has mostly dealt with top-down managed teams from the perspective of top and middle management [c.f. 56], and has mostly ignored the selforganizing, bottom-up way and transparency that AISD methods entail, while a psychologically safe environment, a healthy organizational culture, and open collaboration are seen as key factors for successful AISD teams in practice [19, 41]. Only limited research has taken different viewpoints into consideration [e.g., 2].

These aspects are closely related to viewing AISD as a social process; as AISD is quintessentially a team effort [54], practitioners as well as researchers call for more research on social aspects of AISD teams [18]. We therefore focus on the team's lifecycle, meaning the phases a team experiences when undergoing agile transformation and the barriers along their way, bridging the gap between method tailoring and adoption [e.g., 21] and general change management literature [e.g., 56]. With a more holistic understanding of the AISD team lifecycle and corresponding guidelines, agile transformation processes will no longer resemble a mere heuristic approach and will be less prone to cost-intensive, sub-par agile implementations, or outright failures. In this paper, we therefore address the following research question: How can the lifecycle of AISD teams be described and explained, and which barriers have to be overcome to become agile?

To open up the black box of the lifecycle of AISD teams and the agile transformation process, we conducted an exploratory, multiple case-study across six different organizations. Our inductive, two-step coding process resulted in a set and categorization of threats to the agile transformation process and a phase model describing the lifecycle of AISD teams, including barriers to overcome.

Taken together, we provide novel insights which help practitioners to enhance structure and management of their agile transformation processes, anticipate barriers and threats, and take corrective action to reduce failure rates and increase satisfaction among team members. Further, our results lay the groundwork for extending the body of knowledge of change management and method tailoring to integrate a more holistic view of agile transformations and AISD teams, therefore giving a new line of argument to explain failing and succeeding agile transformation 
processes. lastly, we advance our understanding of team-level effects in AISD, ultimately improving team performance and reducing project failures.

In the following, we give an overview about related work. Then we describe the cases and the coding process. Next, we present our findings. Finally, we discuss our results and their implications.

\section{Related Work and Background}

\subsection{Agile Information System Development and Agile Adoption}

IS are often developed in the form of projects [25], with many involved stakeholders and project team members [7]. The nature of AISD is in many aspects intangible [14], and the major problems of AISD projects are not so much technological as sociological in nature [17]. Coordination and communication are necessary for successful implementation [23, 28], and creating a shared understanding is deemed to be a major driver for AISD success [13, 23, 48].

In practice, approaches for developing IS range from sequential [49] to more cyclic, iterative approaches [4]. AISD methods [e.g., 6] trade strict control for more flexibility and autonomy within the team, the overall development process is not planned and scheduled upfront, and progress is made in small iterative phases, while encouraging change and constant feedback [8]. Planning becomes a permanent task, and team leadership is established via collaboration and is separated from project lead [20].

While the team is thus highlighted as the crucial aspect of AISD in practice, extant research in the field of AISD methods has investigated mainly specific and individual or organizational phenomena, such as the use and effects of specific agile practices [e.g., 1, 40], or effects regarding whole projects or organizations, such as the introduction of AISD methods to teams [e.g., 6, 36] or recently scaling AISD methods to largescale projects $[11,27]$.

As research thus covers the individual and organization-wide level of effects on AISD, team-level effects are covered less so, and existing results are contradictory. Team research has included technology as an influencing factor of team work [e.g., 30], but specific features of AISD have not been observed. Research found that cohesive teams are the optimal base for applying agile practices [6, 22], while other studies suggest that diversity amplifies creativity and problem-solving ability [32, 47] and therefore might provide benefits for AISD. These inconsistencies are especially important for AISD, as AISD teams rely heavily on efficiency [to respond quickly to changes;
9] and problem-solving ability [to complete complex, non-routine tasks; 32].

In regard to the lifecycle of AISD teams, only limited research exists. For instance, Fitzgerald, Hartnett and Conboy [21] observed the customization and tailoring of AISD methods over a period of three years. They found that more development-centric (i.e., stemming from Extreme Programming) and more project-management-centric (i.e., stemming from Scrum) practices tend to create synergetic effects when tailored to the individual needs of a specific needs. Further, they found that these needs may differ drastically among different teams from the same organization. While providing a seminal basis for the adaptation and tailoring process of AISD methods, Fitzgerald, Hartnett and Conboy [21] provide only limited additional insight into the overall transformation process. Similarly, Sarker and Sarker [52] provide insight into the optimal harnessing of AISD methods in geographically distributed projects, but less so in the team's lifecycle and overall transformation process. Iivari and Iivari [26] explain the relationship between organizational culture and AISD methods, especially in emergent stages, but also do not provide insight into the overarching lifecycle of agile transformation.

In sum, extant research does not address differences in lifecycle status, or how to overcome different barriers in different phases. While we focus on information systems development projects, our understanding of AISD includes organizational science's more abstract view of agility as a dynamic capability - therefore suggesting change management research as a building block.

\subsection{Change Management}

Transforming an organization to an agile organization inherently entails change management - the planned transition of an organization from an initial state to a target state, including planning, execution, and control of actions needed to perform this transition. Especially the three-phased model (i.e., CATS) of Lewin [33], the 8-step process of Kotter [29], and the Seven Steps of Luecke [35] have emerged as central, yet abstract theories for explaining and managing organizational change. For instance, especially CATS has been praised [53] as a seminal work, and has been criticized at the same time as being too simplistic [c.f. 15]. Still, these theories remain fundamental works for explaining planned organizational change [c.f. 56].

As these theories are aimed at an universal, abstract team and are designed to be applied independent of the specific environments of a to-be-transformed team, they include processes and influencing factors at a high 
level, such as "create a sense of urgency" as an important process or shifts in strategy, structure, and culture as change evoking factors [56]. While this birds-eye view on change management might not provide a detailed guideline for every specific field, it does provide a baseline framework for other theories.

For the domain of IT-enabled change and building upon general change management literature, Benjamin and Levinson [3] proposed a theory for explaining the differences that IT-enabled change brings compared to change driven by other concerns. Markus and Benjamin [38] have focused more on the social aspect of and roles needed for IT-enabled change, whereas Markus and Robey [37] addressed fundamental questions related to the relationship between technology and change. In sum, these theories do not include a holistic view and employ a mainly top-down, hierarchical view on teams and team management. They do not consider, for instance, how to overcome barriers to become - over time - self-aware, selfreflecting, autonomous, and a continuously refining team.

Considering the literature cited in this section, one might conclude that research on change management has not been actively continued after the late 1990s and followingly has been composed mostly in the context of non-agile teams. We found, however, a recent and upcoming [18] stream of research, targeting large-scale agile transformation [e.g., 11, 27]. Our research question therefore cannot be completely answered directly from extant research on agile methods or change management.

\section{Research Method}

\subsection{Case Overviews and Data Collection}

To answer our research question, we conducted an embedded, exploratory multiple case-study [58] in six different case organizations (see Table 1). The cases were sampled following a theoretical sampling strategy (we expected differences in lifecycle and adoption across the cases). All investigated organizational units are based in Germany. Two of these cases are set in large insurance companies (Insure1 and Insure2), one of which is active internationally and one nationally. The third and fourth cases (Develop1 and Develop2), as contrasts, are set in a small-to-medium sized software development company, focusing on Businessto-Business (B2B) services. Lastly, Consult1 and Consult 2 are two large consulting companies, included as they can give a broader overview over different companies and therefore enrich our data set.

Develop1 and Develop2 started to incorporate agile practices eight years ago. Insure 1 and Insure 2 both are in the process of agile transformation, which started in both cases a little over a year ago. Consult1 provided access to participants who had multiple years of experience working agile for different clients and Consult 2 provided access to agile coaches, which also had multiple years of experience. Due to the popularity of method tailoring [57] instead of "doing agile by the book" and deciding for a singular method, we decided to look at agile on a set of practices level instead of a method level.

Table 1. Case Overviews ${ }^{1}$

\begin{tabular}{|l|c|c|}
\hline \multicolumn{1}{|c|}{ Case } & Industry & Size \\
\hline Insure1 & Insurance & Large \\
\hline Insure2 & Insurance & Large \\
\hline Develop1 & B2B Software & Small to medium \\
\hline Develop2 & B2B Software & Small to medium \\
\hline Consult1 & Consulting & Large \\
\hline Consult2 & Consulting & Large \\
\hline
\end{tabular}

Table 2. Different Teams in Insure1

\begin{tabular}{|l|l|}
\hline \multicolumn{1}{|c|}{ Team } & \multicolumn{1}{c|}{ Description } \\
\hline Transformation & $\begin{array}{l}\text { Oversees the overall agile } \\
\text { transformation process; guides and } \\
\text { introduces new teams to agile } \\
\text { workflows }\end{array}$ \\
\hline Development & Agile software development team \\
\hline Ecosystem & $\begin{array}{l}\text { Cross-functional ecosystem team; } \\
\text { "test balloon" for rolling out } \\
\text { product-oriented, cross-functional } \\
\text { teams }\end{array}$ \\
\hline Waterfall* & $\begin{array}{l}\text { A team that tried to implement agile } \\
\text { methods, but returned to waterfall- } \\
\text { like, non-iterative work. }\end{array}$ \\
\hline
\end{tabular}

We collected data from various data sources and with different data collection methods. Semi-structured interviews ${ }^{2}$ and project documentation were used to generate data. We interviewed both project managers and project workers. ${ }^{3}$ Administrative documents, work descriptions, interview transcripts, and field notes were collected in a case study database. The selection of interview participants was based on the aforementioned work descriptions and administrative documents to cover common roles in AISD projects, but also to interview those team members, which can give detailed insight in and an overview of current and recent projects.

\footnotetext{
${ }^{1}$ For additional case details see https://osf.io/fjq5e/

${ }^{2}$ For details on the guideline see https://osf.io/tkjvf/

${ }^{3}$ For further informant details see https://osf.io/k2ncw/
} 
We collected data from July 2018 to March 2019 while conducting 39 interviews at the organizations' site or via calls. The guideline was not shared with the interviewees and we only used it as a checklist and outline. The aim was to encourage the interviewees to provide a narrative of their experiences as freely as possible. Participants from the transformation team of Insure1 (see Table 2) and all participants of Insure2 enabled us to gain an overview over all agile teams and, more importantly, were able to tell us about any "Lessons Learned", as they were part of an agile transformation team. All other participants were part of development teams. Other documentation (e.g., work descriptions) were used to set the interviews into context.

While loosely following the guideline, space for probing and open questions was available. During these interviews, the participants were asked about the implemented agile practices and about teamwork in general. Further, we asked participants about their perceptions of the applicability and success of agile practices as well as team climate and interactions between team members. The interviews lasted about 60 minutes and were recorded and transcribed. This resulted in about 605 recorded transcript pages (letter format). Follow-up e-mails were sent to request clarifications and to offer informants the possibility to provide feedback and comments.

The interview protocol and guideline were checked against Bouchard [5] and Mishler [43]. The guideline was especially checked regarding the sequence of questions; however, since the interviews were basically open, as few direct questions as possible were asked and leading questions were avoided [34].

\subsection{Data Analysis}

Following Saldaña [50], we applied different coding strategies. At the core is the task of conceptualization, that is, "the process of grouping similar items according to some defined properties and giving the items a name that stands for that common link" [55]. As coding can be seen as "cyclical act" [50], our coding process therefore can be distinguished between a first and second step, with multiple iterations of each step involved to, for instance, resolve discrepancy between coders. The coding was performed by two researchers. Coding techniques and checklists $[45,61]$ were used to derive conclusions from the data. The data analysis process is outlined in Figure 1.

During the first step we conducted "Initial Coding". Initial Coding helps to organize and break down the data into discrete parts [50]. This approach helps to reflect deeply on the contents and nuances while remaining open to all other possible leads in the data. In parallel, we conducted "Process Coding" - an approach to identify consequences of action or interaction [50]. Process coding focuses in more detail on helping the researcher to reflect on activity and conceptual action. Taken together, this first cycle of coding (i.e., initial and process coding), helped us "digest" the gathered data, structure it in a way that prepares for the following, more detailed analysis.

The following, second cycle coding method,

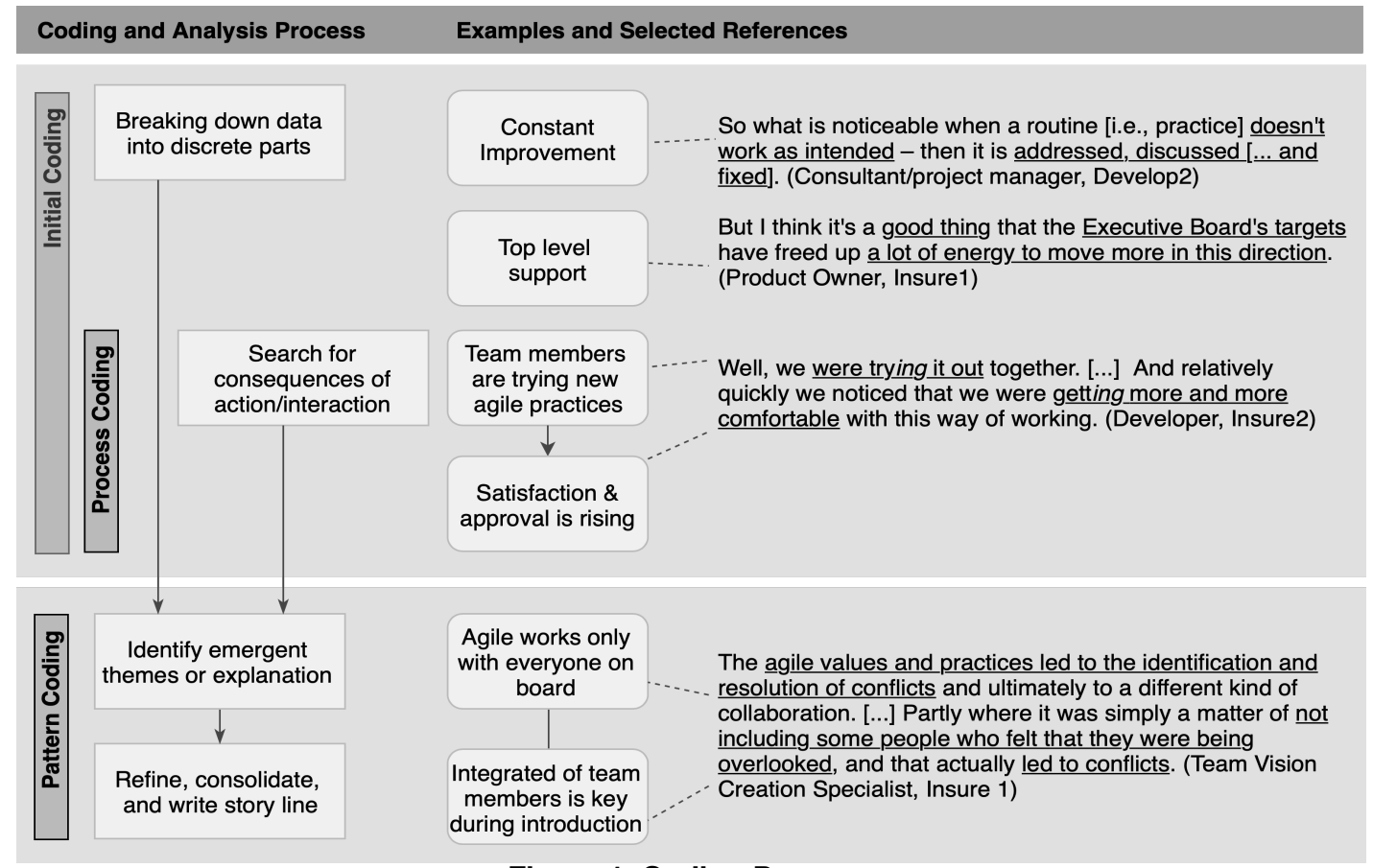

Figure 1. Coding Process 
"pattern coding", is appropriate for the development of major themes from data [42, 50]. These codes are capable to "identify an emergent theme" and therefore are helpful for "grouping those summaries into a smaller number of sets, themes, or constructs" [42]. We tried to group our descriptive codes into meaningful pattern codes by combining similar (e.g., "constant improvement" and "continuous improvement") as well as supplementary codes (e.g., "change is easier for "young", and "change is more difficult for "old"').

We completed the coding process with a final step, in which we did some post-coding activities such as fine-tuning of the wording and alphabetical order of the results.

\section{Results}

\subsection{Threats to Agile Transformation}

Based on the interviews and the resulting coding, two main results were derived. First, a categorization of factors influencing the implementation and adaptation of agile methods (i.e., "threats") has been extracted. The resulting categories and exemplary factors, as well as exemplary quotes are listed in Table 3.

We identified four overarching categories. First, we identified threats from the team's environment (e.g., missing top management support, unclear goals, or a works council, that hinders the agile expansion):

"But I think it's a good thing that the management's guidelines made a lot of room for maneuver to move more in this [i.e., agile] direction [...] if it hadn't been for that, it wouldn't have worked." (Product Owner, Insure1)

Second, we identified threats related to personal effects of individual team members (e.g., that older team members found agile transformation generally speaking more difficult than younger ones, incompatible character attributes among team members leading to (emotional) conflict, general fear of change, or (task) conflict arising from excluding team members from decision making processes):

"We have an average age in IT of over 50. No kidding. It's quite easy for some to say "oh, the few years I'm around, I won't do that to myself no more" It's not everyone's way of thinking and that's a little black-andwhite, but it's a not uncommon." (Product Owner, Insure1)

Third, we identified threats arising from the process of agile transformation or AISD itself (e.g., stemming from frustration of rituals that were perceived as "unnecessary", the unwillingness to transition to a more transparent workflow, the incompatibility of agile processes to those of adjacent teams, or insufficiently allocated resources):

"The whole situation has changed because previously we were all in it [the team] between 50\% and 70\% of our capacity. [...] And recently I and another colleague got bumped up to $100 \%$ and all other colleagues to $80 \%$. You can already tell now that there is much more room to engage with this topic." (Specialist for Product Management, Insure1)

Fourth, we identified threats stemming from the team itself (e.g., a missing common language in the team or political fights of team members that demoralized other team members). These threats were especially salient early after the beginning of the agile transformation and less so for more experienced teams. Similarly, only those threats that include any decision maker (e.g., top management, team leaders) were visible before the initial decision to begin an agile transformation was made:

"We want to work together [cross-functionally] and we have to find a common language, right? And that wasn't the case in the past. And without the common language it won't work." (Team Lead, Insure2)

Table 3. Exemplary Threats by Category

\begin{tabular}{|c|c|c|}
\hline Category & $\begin{array}{l}\text { Exemplary } \\
\text { Threats }\end{array}$ & Exemplary Quote \\
\hline \multirow[t]{3}{*}{ Environment } & $\begin{array}{l}\text { Missing top } \\
\text { management } \\
\text { support/invest } \\
\text { [known issue; } \\
\text { e.g, 16, 39] }\end{array}$ & $\begin{array}{l}\text { "I know that other } \\
\text { departments, or other } \\
\text { executives, are quite } \\
\text { skeptical of this [...]. So } \\
\text { that's certainly a } \\
\text { concern." (Specialist for } \\
\text { Product Management, } \\
\text { Insure1) }\end{array}$ \\
\hline & $\begin{array}{l}\text { Top } \\
\text { management } \\
\text { goals are } \\
\text { unclear } \\
{[\text { known issue; }} \\
\text { e.g, 16] }\end{array}$ & $\begin{array}{l}\text { "Well, one rarely really } \\
\text { talks about it that } \\
\text { consciously. [...] We're } \\
\text { currently just trying to get } \\
\text { our work done } \\
\text { somehow." (Developer, } \\
\text { Insure1) }\end{array}$ \\
\hline & $\begin{array}{l}\text { Works council } \\
\text { hinders agile } \\
\text { expansion } \\
\text { (new) }\end{array}$ & $\begin{array}{l}\text { "This [agile work] is also } \\
\text { something they don't } \\
\text { necessarily want." } \\
\text { (Specialist for IT } \\
\text { Portfolio Management, } \\
\text { Insure1) }\end{array}$ \\
\hline \multirow[t]{2}{*}{ Personal } & $\begin{array}{l}\text { Change is easier } \\
\text { for "young", } \\
\text { more difficult } \\
\text { for "old" } \\
\text { [known issue; } \\
\text { e.g, 16] }\end{array}$ & $\begin{array}{l}\text { "So, I'm not going to get } \\
\text { the } 55 \text { to } 60 \text { year old } \\
\text { Cobol developers } \\
\text { together here and try to } \\
\text { teach them Scrum. That's } \\
\text { not going to work." } \\
\text { (Program Manager, } \\
\text { Insure2) }\end{array}$ \\
\hline & $\begin{array}{l}\text { Character } \\
\text { attributes }\end{array}$ & $\begin{array}{l}\text { "It depends on the way } \\
\text { people are. [...] It's the }\end{array}$ \\
\hline
\end{tabular}




\begin{tabular}{|c|c|c|}
\hline & $\begin{array}{l}\text { incompatible } \\
\text { among team } \\
\text { members } \\
\text { (new) }\end{array}$ & $\begin{array}{l}\text { human factor - how are } \\
\text { people socialized? How } \\
\text { open are they? How can } \\
\text { you work with them?" } \\
\text { (Agile Coach, Consult 2) }\end{array}$ \\
\hline & $\begin{array}{l}\text { Fear of change } \\
{[\text { known issue; }} \\
\text { e.g, 16, 29, 39] }\end{array}$ & $\begin{array}{l}\text { "If you've been working } \\
\text { this way for years and } \\
\text { you think "oh here I've } \\
\text { done a really good job" } \\
\text { and someone comes } \\
\text { along and says "that } \\
\text { wasn't good at all, we } \\
\text { should work in a } \\
\text { completely different way" } \\
\text { - that's very difficult for } \\
\text { people to handle, isn't it? } \\
\text { To accept that first." } \\
\text { (Team Lead, Insure2) }\end{array}$ \\
\hline & $\begin{array}{l}\text { Team members } \\
\text { not included in } \\
\text { decision making } \\
\text { processes } \\
\text { [known issue; } \\
\text { e.g, 16, 29] }\end{array}$ & $\begin{array}{l}\text { "Partly where it was } \\
\text { simply that some [team } \\
\text { members] were not } \\
\text { included and felt ignored } \\
\text { - that actually led to } \\
\text { rejection and conflict." } \\
\text { (Team Vision Specialist, } \\
\text { Insure1) }\end{array}$ \\
\hline \multirow[t]{3}{*}{ Process } & $\begin{array}{l}\text { "Unnecessary" } \\
\text { rituals are } \\
\text { hurting the } \\
\text { transformation } \\
\text { and acceptance } \\
\text { (new) }\end{array}$ & $\begin{array}{l}\text { "And their rituals are } \\
\text { handled very strongly and } \\
\text { strictly, which naturally } \\
\text { then leads to questions } \\
\text { and partly also to } \\
\text { irritations with new } \\
\text { colleagues, if they } \\
\text { perceive the rituals as } \\
\text { redundant." (Change } \\
\text { Management Specialist, } \\
\text { Insure1) }\end{array}$ \\
\hline & $\begin{array}{l}\text { Agile creates } \\
\text { unwanted } \\
\text { transparency } \\
\text { (new) }\end{array}$ & $\begin{array}{l}\text { "You also have to coach } \\
\text { the people so that they do } \\
\text { it right, because a lot of } \\
\text { people feel that they are } \\
\text { somehow being watched. } \\
\text { Actually, it's something } \\
\text { quite intriguing if you } \\
\text { say, "I'm working on this } \\
\text { and that", but the next } \\
\text { one already thinks, if he } \\
\text { doesn't name at least five } \\
\text { items next, then the boss } \\
\text { thinks, "that's terrible, } \\
\text { you did too less. You } \\
\text { didn't accomplish } \\
\text { anything." (Team Lead, } \\
\text { Develop2) }\end{array}$ \\
\hline & $\begin{array}{l}\text { Agile does not } \\
\text { fit into "old" } \\
\text { processes } \\
(\text { new) }\end{array}$ & $\begin{array}{l}\text { "If virtually all of the } \\
\text { environment is prioritized } \\
\text { [i.e. organized] } \\
\text { differently, then it is } \\
\text { difficult for me to do } \\
\text { anything with any } \\
\text { methodology, and that } \\
\text { cannot be blamed on an }\end{array}$ \\
\hline
\end{tabular}

\begin{tabular}{|c|c|c|}
\hline & & $\begin{array}{l}\text { agile methodology itself." } \\
\text { (IT Specialist, Insure1) }\end{array}$ \\
\hline & $\begin{array}{l}\text { Increases } \\
\text { communication } \\
\text { might be } \\
\text { slowing down } \\
\text { the overall } \\
\text { process } \\
(\text { new) }\end{array}$ & $\begin{array}{l}\text { "It helps but has also } \\
\text { recently led to problems. } \\
\text { [...] There have come up } \\
\text { some discussions more } \\
\text { often than not that would } \\
\text { not have been necessary } \\
\text { at all." (Team Lead, } \\
\text { Develop2) }\end{array}$ \\
\hline \multirow[t]{3}{*}{ Team } & $\begin{array}{l}\text { Commitment to } \\
\text { the cause is } \\
\text { critical } \\
\text { [known issue; } \\
\text { e.g, 16, 29] }\end{array}$ & $\begin{array}{l}\text { "You have to commit } \\
\text { yourself [...], this is an } \\
\text { attitude and mindset } \\
\text { matter [...]. This is not } \\
\text { quite common here." } \\
\text { (Specialist for Product } \\
\text { Management, Insure1) }\end{array}$ \\
\hline & $\begin{array}{l}\text { Common } \\
\text { language needs } \\
\text { to be developed } \\
\text { [known issue; } \\
\text { e.g, 16] }\end{array}$ & $\begin{array}{l}\text { "If everyone knows } \\
\text { something different, if } \\
\text { everyone perhaps also } \\
\text { has a different language } \\
\text { usage, if one talks about } \\
\text { something - that just } \\
\text { makes it more difficult." } \\
\text { (Developer, Insure1) }\end{array}$ \\
\hline & $\begin{array}{l}\text { Political fights } \\
\text { in the team hurt } \\
\text { the } \\
\text { transformation } \\
\text { [known issue; } \\
\text { e.g, 16, 39] }\end{array}$ & $\begin{array}{l}\text { "Honestly, by having had } \\
\text { a few power fights within } \\
\text { the team for a while, we } \\
\text { did lose some progress." } \\
\text { (IT Specialist, Insurel) }\end{array}$ \\
\hline
\end{tabular}

The threats displayed in Table $\mathbf{3}$ vary across our cases, however, we did not find an indication that one of these threats can only apply to one of the barriers. While Develop1 and Develop2 showed nearly no indication of issues regarding top management, both Insure1 and Insure2 showed much more salient issues. This is mostly grounded in the organizational size and hierarchy - Develop1 and Develop2 have only two levels of hierarchy. Similarly, the fear of unwanted transparency was much higher in Insure1 and Insure2. This can, as multiple interviewees described, be traced back to the motivation many of the employees had when choosing the insurance industry (safety, security, and stability):

"Why does one choose to go work in insurance? One likes to have stability." (Initial Team Set-Up Specialist, Insure1)

Opening up workflows and making one's own work much more transparent inherently reduces safety, security, and stability, and therefore might pose a threat to an employee:

"Some say, 'I don't even want that freedom!'” (Initial Team Set-Up Specialist, Insure1) 
Further, the mean age of employees was much higher in Insure1 and Insure 2 than in Develop1 and Develop2. This had a profound effect on the threats related to age: No participant from Develop1 or Develop2 indicated that AISD methods were adopted better depending on age, while nearly every participant from Insurel and Insure2 did so:

"Many have spent 20 or 30 years working like this [the waterfall model] and are now thinking "why should I change at all?"' (Developer, Insure1)

\subsection{A Lifecycle Model of Agile}

As a second result, we propose a phase model of agile implementation and adaptation, including possible return paths to non-agile work. Figure 2 summarizes the model.

Based on the similarities and differences in implementation strategies and the resulting states of work processes, we derived phases and transitions as mentioned by participants during interviews. All cases mentioned some state of Non-Agile Work - a waterfall driven approach, and a very early non-structured "startup" phase for Develop1 and Develop2. All cases experienced an initial "spark" or interest in agile methods, such as Insure1:

"There was a change in the executive board, and they issued the directive to have 80 teams transformed to agile before the end of the year." (Specialist for IT Portfolio Management, Insure 1)

This interest led all cases to undergo a Preparation phase. In Insure 1, this was mainly due to difficulties implementing agile and the following reexamination of their transformation procedure:

"The transformation was nicely planned like a waterfall. At some point, everyone saw that it just did not work that way. Then the management board switched from a push to pull strategy - so the teams just had to signal interest, not the leadership." (Specialist for IT Portfolio Management, Insure 1)

With this change in procedure, Insure1 overcame the first barrier: the decision to discard the idea of agile methods or to go agile and find the support to implement changes.

Having overcome this first barrier, all cases described an exploratory Implementation phase. Transforming and setting up was described as individual, heuristic approaches for each team. This phase is characterized by the process of trying to find a "modus operandi", a set of agile practices, mindset, and roles matching the team's individual needs:

\begin{abstract}
"We used the retrospectives to discuss the ways of working together [and] simply familiarize ourselves with the methodology and then said: Yes, here it fits well, elsewhere we have to adapt." (Specialist for Customer Management, Insure 1)
\end{abstract}

This process was in all cases described as not only iterative, but sometimes as time consuming:

\section{"But for that you need a certain perseverance here as well." (Agile Coach, Consult2) \\ "It just takes time." (Team Vision Specialist, Insure1)}

Only one team has - after multiple iterations - decided to discard agile methods and return to non-agile work. All other teams overcame the second barrier. While the first barrier is characterized by the dependency on management or leadership support to allow and consciously try to implement agile methods, the second barrier is described by building support and acceptance in the teams and convincing the team members.

"Right now, we're trying to tear down walls and take people by the hand and show them that's actually not so

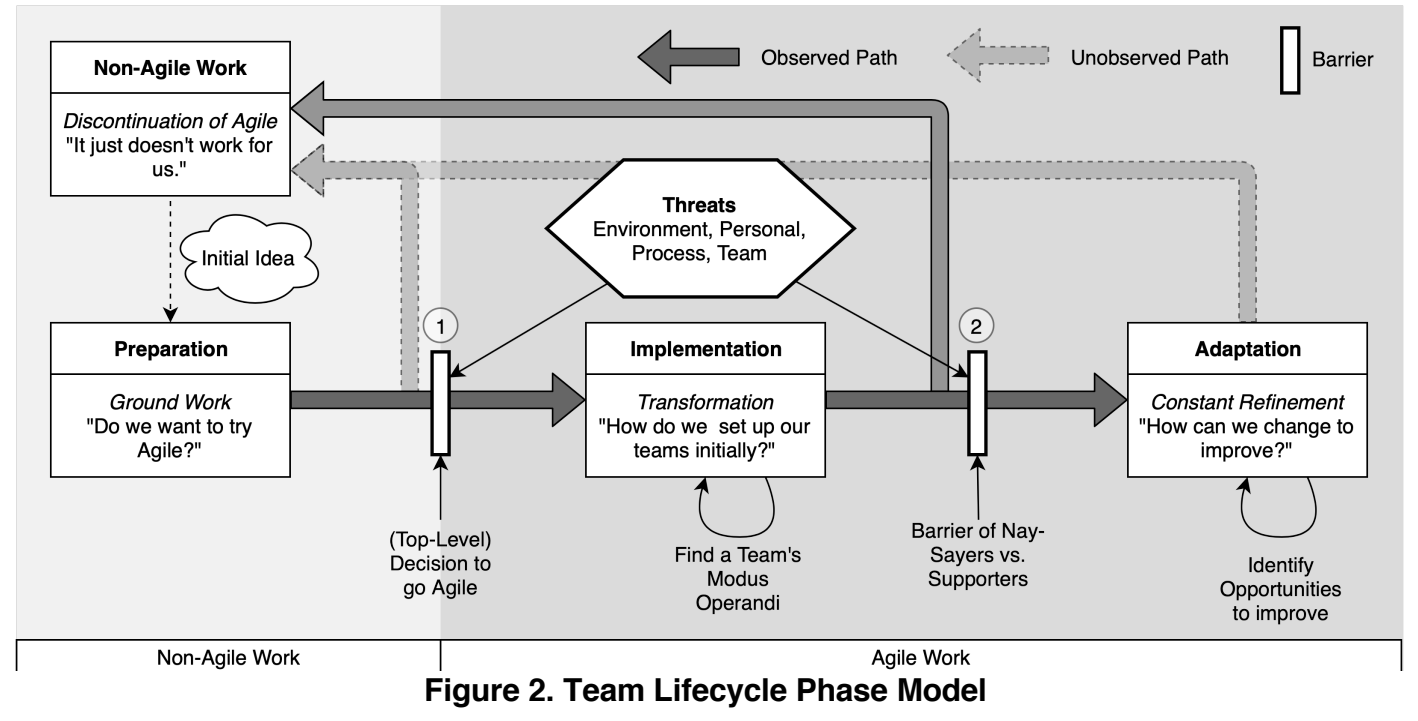




\section{bad at all." (Digital Officer, Insure2)}

"We also had skeptics among us who are now fully committed to the team. [...] we suffered long enough, so to speak, and we really put enthusiasm and heart and soul into it." (Agile Coach, Consult2)

Having overcome the second barrier, the teams entered a phase of Adaptation. This phase is characterized by constant refinement and iterative improvement by changing and adjusting the current work mode. Roger from Insure1 describes this as follows:

\begin{abstract}
"This [initial implementation] was followed by a time when each team member was positioning themselves to a certain extent in the team. You also became more aware of their personal characteristics. And then the retrospective was more like this... Now not to affect only the personal level, but now that we had to talk very, very clearly about who cares about what in the team? And how do they want to ultimately work together?" (Specialist for Customer Management, Insure1)
\end{abstract}

As for the other aspects of this phase model, we found evidence for this lasting, constant iterative mode of improvement in other cases. For instance, in Insure2 or Develop2:

"And since then we have had the opportunity to focus much more on retro[spective]. Following the theme "let's think about where we want to change and improve the process further." (Scrum Master, Insure2)

"Then someone made a suggestion. We gave it a try. We agreed that it would work well or not. The things that worked well were kept, were perhaps also modified a little to fit the situation. And so, it simply evolved over time." (Project Manager, Develop2)

\section{Discussion}

Many of the above described threats are known from general change management literature. Similarly, many of the corrective actions taken by any of our case organizations are known. However, all participants from an agile transformation team or those who stated to have worked as a Scrum master reported that all corrective actions were based on experience and were mostly of heuristic nature - an AISD lifecycle framework combining extant knowledge from change management literature and the specifics of agile transformation has not been known, but was reported to be highly demanded. Such a framework was requested to help management to better anticipate the transformation process, prepare for threats, and ultimately improve the success of agile transformation processes.

As described in the previous section, many of the differences in salient threats to agile transformation were related to the size and history of the organization, we would still argue for the benefits of a generalized lifecycle model for AISD teams as provided above. We acknowledge the need for additional research on identifying different classes of threats and for which organizations they apply, but we see this study as an extensible base model. Further, the more abstract nature of this model enables an easier overview and adaptation for both research and practice.

However, this research is not without limitations. First, all of our cases are based in Germany. Therefore, our results might not be completely transferable to other regions and cultures. Future research could conduct similar studies in other countries and cultural regions to strengthen the confidence in our results or to add boundary conditions to the lifecycle model.

Second, we did not collect data longitudinally but only once per team. While we did ask each participant to describe the history of the team, the memories might have been distorted. However, as we collected data at multiple points in time for each case (e.g., over a span of 10 months for Insure1) and due to the homogeneous statements retrieved from participants, we believe this to be a minor influence on our results.

Third, we did not conduct interviews with every team member. It is likely that the perceptions of the specific team's success and especially its social structure varies. We believe this difference to be of only peripheral nature and to not have a significant effect on our conclusions due to the very homogeneous nature of the statements in all interviews.

Fourth, while all cases used similar sets of SAPs (see online material extending Table 1), they still had differences. For instance, only Develop1 and Develop2 used collective code ownership. This practice could lead to more communication among team members, discussing, for instance, code changes, but could also have no effect, as we did not find evidence for a singular effect of this practice. Further research is therefore warranted.

The fifth limitation is the influence of social desirability bias, as it is generally more socially desirable to report success rather than failure. Nederhof [44] suggests postulating questions that are neutral. We tried to minimize the social desirability bias emerging from our questions. However, due to the clear preferability of success over failure, social desirability bias was still likely to emerge from questions during our interviews.

\section{Conclusion}

In this paper, we derived a phase model, building upon and assembling extant literature, to explain the agile transformation process and the lifecycle of AISD teams. Based on 33 interviews with 39 participants 
across six case organizations from a variety of industries, we are confident to have found reliable and useful insights. We gave an overview over the basic literature regarding AISD and change management and described our research process. The phase model was explained and threats to a successful agile transformation were given to raise awareness and prepare for corrective action (e.g., by discussing the fear of transparency early and extensively or to decide early whether or not AISD is suitable for the team). It therefore bridges the gap between high-level, abstract change management models, and detailed agile method tailoring models.

Based on this model, we wage to answer the question raised in our title: while avenues exist for exiting an agile transformation process, successful transformation depends in many ways on broad support and being "in for a pound".

\section{Acknwledgements}

The German Research Foundation (DFG) funded parts of this study under record no. RO 3650/8-1.

\section{References}

[1] Balijepally, V., et al.: Are Two Heads Better than One for Software Development? The Productivity Paradox of Pair Programming. MIS Quarterly 33, (2009), pp. 91-119

[2] Barker, J.R.: Concertive control in the self-managing organization: Changes in communication and control practices during a period of organizational transformation. University of Colorado (1993)

[3] Benjamin, R.I., Levinson, E.: A framework for managing IT-enabled change. Sloan Management Review 34, (1993), pp. 23-33

[4] Boehm, B.W.: A Spiral Model of Software Development and Enhancement. IEEE Computer 21, (1988), pp. 61-72

[5] Bouchard, T.J.: Field Research Methods: Interviewing, Questionnaires, Participant Observation, Systematic Observation, Unobtrusive Measures. In: Dunnette, M.D. (ed.) Handbook of lndustrial and Organizational Psychology. Rand McNally, Chicago, IL, USA (1976)

[6] Cao, L., et al.: A framework for adapting agile development methodologies. European Journal of Information Systems 18, (2009), pp. 332-343

[7] Chae, B., Poole, M.S.: The surface of emergence in systems development: agency, institutions, and large-scale information systems. European Journal of Information Systems 14, (2005), pp. 19-36

[8] Cockburn, A., Highsmith, J.: Agile Software Development: The People Factor. IEEE Computer 34, (2001), pp. 131-133
[9] Conboy, K.: Agility from First Principles: Reconstructing the Concept of Agility in Information Systems Development. Information Systems Research 20, (2009), pp. 329-355

[10] Conboy, K., Fitzgerald, B.: Method and developer characteristics for effective agile method tailoring: A study of XP expert opinion. ACM Transactions on Software Engineering and Methodology (TOSEM) 20, (2010), pp. 2

[11] Conboy, K., Carroll, N.: Implementing Large-Scale Agile Frameworks: Challenges and Recommendations. IEEE Software 36, (2019), pp. 44-50

[12] Conforto, E.C., et al.: Can agile project management be adopted by industries other than software development? Project Management Journal 45, (2014), pp. 21-34

[13] Corvera Charaf, M., et al.: The emergence of shared understanding: Applying functional pragmatics to study the requirements development process. Information Systems Journal 23, (2013), pp. 115-135

[14] Cule, P., et al.: Strategies for Heading off IS Project Failure. Information Systems Management 17, (2000), pp. $65-73$

[15] Cummings, S., et al.: Unfreezing change as three steps: Rethinking Kurt Lewin's legacy for change management. Human relations 69, (2016), pp. 33-60

[16] Cummings, T.G., Worley, C.G.: Organization development and change. Cengage learning (2014)

[17] DeMarco, T., Lister, T.: Peopleware: productive projects and teams. Dorset House Publishing Co., Inc. New York, NY, USA (1987)

[18] Diegmann, P., et al.: Journey Towards Agility: Three Decades of Research on Agile Information Systems Development. In: International Conference on Information Systems, (2018)

[19] Dora, Google Cloud: The 2019 Accelerate State of DevOps. (2019)

[20] Dybå, T., Dingsøyr, T.: Empirical studies of agile software development: A systematic review. Information and software technology 50, (2008), pp. 833-859

[21] Fitzgerald, B., et al.: Customising agile methods to software practices at Intel Shannon. European Journal of Information Systems 15, (2006),

[22] Fruhling, A., de Vreede, G.-J.: Field Experiences with eXtreme Programming: Developing an Emergency Response System. Journal of Management Information Systems 22, (2006), pp. 39-69

[23] Gallivan, M.J., Keil, M.: The user-developer communication process: a critical case study. Information Systems Journal 13, (2003), pp. 37-68

[24] Gregory, P., et al.: The challenges that challenge: Engaging with agile practitioners' concerns. Information and Software Technology 77, (2016), pp. 92-104

[25] Hirschheim, R., et al.: Information Systems Development and Data Modeling. Conceptual and 
Philosophical Foundations. Cambridge University Press, Cambridge, England (1995)

[26] Iivari, J., Iivari, N.: The relationship between organizational culture and the deployment of agile methods. Information and Software Technology 53, (2011), pp. 509520

[27] Kalenda, M., et al.: Scaling agile in large organizations: Practices, challenges, and success factors. Journal of Software: Evolution and Process 30, (2018), pp. e1954

[28] Ko, D.-G., et al.: Antecedents of Knowledge Transfer from Consultants to Clients in Enterprise System Implementations. MIS Quarterly 29, (2005), pp. 59-85

[29] Kotter, J.P.: Leading change: Why transformation efforts fail. Harvard Business Review (1995),

[30] Kozlowski, S.W., Ilgen, D.R.: Enhancing the Effectiveness of Work Groups and Teams. Psychological Ccience in the Public Interest 7, (2006), pp. 77-124

[31] Laanti, M., et al.: Agile methods rapidly replacing traditional methods at Nokia: A survey of opinions on agile transformation. Information and Software Technology 53, (2011), pp. 276-290

[32] Lee, G., Xia, W.: Toward Agile: An Integrated Analysis of Quantitative and Qualitative Field Data on Software Development Agility. MIS Quarterly 34, (2010), pp. 87-115

[33] Lewin, K.: Group decision and social change. Readings in social psychology 3, (1947), pp. 197-211

[34] Loftus, E.: Leading Questions and the Eye Witness Report. Cognitive Psychology 7, (1975), pp. 560-572

[35] Luecke, R.: Managing change and transition. Harvard Business Press (2003)

[36] Mangalaraj, G., et al.: Acceptance of software process innovations - the case of extreme programming. European Journal of Information Systems 18, (2009), pp. 344-354

[37] Markus, M.L., Robey, D.: Information Technology and Organizational Change: Causal Structure in Theory and Research. Management Science 34, (1988), pp. 583-598

[38] Markus, M.L., Benjamin, R.I.: The magic bullet theory in IT-enabled transformation. Sloan management review 38, (1997), pp. 55-68

[39] Markus, M.L.: Technochange management: using IT to drive organizational change. Journal of Information technology 19, (2004), pp. 4-20

[40] Maruping, L.M., et al.: Role of collective ownership and coding standards in coordinating expertise in software project teams. European Journal of Information Systems 18, (2009), pp. 355-371

[41] McGregor, L., Doshi, N.: Why Agile Goes Awry — and How to Fix It. Harvard Business Review (2018),

[42] Miles, M.B., Huberman, A.M.: Qualitative data analysis : an expanded sourcebook. Sage Publications, Thousand Oaks (1994)
[43] Mishler, E.G.: Research interviewing: context and narrative. Harvard University Press, Cambridge, MA, USA (1986)

[44] Nederhof, A.J.: Methods of coping with social desirability bias: A review. European journal of social psychology 15, (1985), pp. 263-280

[45] Paasivaara, M., et al.: Integrating global sites into the lean and agile transformation at ericsson. In: 2013 IEEE 8th International Conference on Global Software Engineering, pp. 134-143.IEEE (2013)

[46] Persson, J.S., et al.: Agile distributed software development: enacting control through media and context. Information Systems Journal 22, (2012), pp. 411-434

[47] Phillips, K.W., et al.: Surface-level diversity and decision-making in groups: When does deep-level similarity help? Group processes \& intergroup relations 9, (2006), pp. 467-482

[48] Rosenkranz, C., et al.: Language Quality in Requirements Development: Tracing Communication in the Process of Information Systems Development. Journal of Information Technology 28, (2013), pp. 198-223

[49] Royce, W.W.: Managing the Development of Large Software Systems: Concepts and Techniques. In: Proceedings of WesCon, (1970)

[50] Saldaña, J.: The coding manual for qualitative researchers. SAGE, London (2016)

[51] Sarker, S., et al.: Assessing the relative contribution of the facets of agility to distributed systems development success: an Analytic Hierarchy Process approach. European Journal of Information Systems 18, (2009), pp. 285-299

[52] Sarker, S., Sarker, S.: Exploring agility in distributed information systems development teams: An interpretive study in an offshoring context. Information Systems Research 20, (2009), pp. 440-461

[53] Schein, E.H.: Kurt Lewin's change theory in the field and in the classroom: Notes toward a model of managed learning. Systems practice 9, (1996), pp. 27-47

[54] Siau, K., et al.: Toward a Unified Model of Information Systems Development Success. Journal of Database Management 21, (2010), pp. 80-101

[55] Strauss, A., Corbin, J.: Basics of qualitative research. Sage, London (1998)

[56] Todnem By, R.: Organisational change management: A critical review. Journal of Change Management 5, (2005), pp. 369-380

[57] VersionOne: 12th State of Agile Report. (2018) https://explore.versionone.com/state-of-agile/versionone12 th-annual-state-of-agile-report

[58] Yin, R.K.: Case Study Research: Design and Methods. SAGE Publications, Thousand Oaks, CA, USA et al. (2003) 